\title{
Unlocking the Mystery of the Therapeutic Effects of Chinese Medicine on Cancer
}

\begin{abstract}
Shao-Hsiang Liu ${ }^{1,2 *}$, Po-Sheng Chen ${ }^{3}$, Chun-Chieh Huang ${ }^{4}$, Yi-Tu Hung ${ }^{5}$, Mei-Ying Lee ${ }^{6}$, Wei-Hung Lin ${ }^{7}$, Yuan-Chuan Lin $^{8}$ and Alan Yueh-Luen Lee ${ }^{9,10 * t}$

${ }^{1}$ Celgen Biotech, Taipei, Taiwan, ${ }^{2}$ Taiwan Instrument Research Institute, National Applied Research Laboratories, Zhubei, Taiwan, ${ }^{3}$ Jing-Her Chinese Medicine Clinic, Taipei, Taiwan, ${ }^{4}$ Department of Chinese Medicine, Taitung Christian Hospital, Taitung, Taiwan, ${ }^{5} \mathrm{HanPoo}$ Chinese Medical Clinic, Taipei, Taiwan, ${ }^{6}$ Chinese Medicine Women Doctors Association, Taipei, Taiwan, ${ }^{7}$ Central Clinic \& Hospital, Taipei, Taiwan, ${ }^{8}$ Taipei Chinese Medical Association, Taipei, Taiwan, ${ }^{9}$ National Institute of Cancer Research, National Health Research Institutes, Miaoli, Taiwan, ${ }^{10}$ Graduate Institute of Biomedical Sciences, China Medical University, Taichung, Taiwan
\end{abstract}

OPEN ACCESS

Edited by:

Ke-Wu Zeng,

Peking University, China

Reviewed by:

Mingyao Gu,

Shenzhen University, China

Shu Wang,

Fudan University, China

*Correspondence:

Shao-Hsiang Liu

liu.shawn@gmail.com

Alan Yueh-Luen Lee

alanylee@nhri.edu.tw

tORCID:

Alan Yueh-Luen Lee orcid.org/0000-0003-0252-0571

Specialty section:

This article was submitted to

Ethnopharmacology,

a section of the journal

Frontiers in Pharmacology

Received: 01 September 2020

Accepted: 05 November 2020

Published: 15 January 2021

Citation:

Liu S-H, Chen P-S, Huang C-C, Hung $Y$-T, Lee $M-Y$, Lin W-H, Lin Y-C and Lee AY-L (2021) Unlocking the Mystery of the Therapeutic Effects of

Chinese Medicine on Cancer.

Front. Pharmacol. 11:601785.

doi: 10.3389/fphar.2020.601785
Over the past decade, the rise of cancer immunotherapy has coincided with a remarkable breakthrough in cancer therapy, which attracted increased interests in public. The scientific community clearly showed that the emergence of immunotherapy is an inevitable outcome of a holistic approach for cancer treatment. It is well established that traditional Chinese medicine (TCM) utilizes the principle of homeostasis and balance to adjust the healthy status of body. TCM treatment toward cancer has a long history, and the diagnosis and treatment of tumors were discussed in the ancient and classical literatures of Chinese medicine, such as the Yellow Emperor's Inner Canon. Precious heritage has laid the foundation for the innovation and development of cancer treatment with TCM. The modern study indicated that TCM facilitates the treatment of cancer and enhances the survival rate and life expectancy of patients. However, the pharmacological mechanisms underlying these effects are not yet completely understood. In addition, physicians cannot always explain why the TCM treatment is effective and the mechanism of action cannot be explained in scientific terms. Here, we attempted to provide insights into the development of TCM in the treatment and interpret how TCM practitioners treat cancer through six general principles of TCM by using modern scientific language and terms based on newly discovered evidence.

Keywords: traditional Chinese medicine, cancer treatment, holistic approach, tumor microenvironment, cancer immunotherapy

\section{INTRODUCTION}

Cancer is a complex and confusing disease. As the number of in-depth studies increases, cancer becomes more difficult to classify and understand for therapy (Hoadley et al., 2018). Although many new drugs targeting cancer have been developed, researchers are unable to keep pace with variable and highly-evolving cancer (Gatenby, 2009; Hanahan and Weinberg, 2011; Willyard, 2016; McGranahan and Swanton, 2017). For instance, variations in the tumor microenvironment (TME), the changes in tumor metabolism, and the development of immunoescape in TME have become unsolved topics that impede us to deal with caancer (Vander Heiden and DeBerardinis, 2017; Jiménez-Sánchez et al., 2017; Zhuang et al., 2019). 
In the past decade, there are enormous changes and revolutionary progressions occur in the area of cancer treatment, including the rise of cancer immunotherapy (Wei et al., 2018). However, cancer immunotherapy alone showed a low response rate and is only suitable to a small proportion of patients (Allison et al., 2020). The combination of other therapies with immunotherapy has recently been proved to be effective for increasing the cancer cure rate (Sharma and Allison, 2015; Swart et al., 2016). In addition, the efficacy of cancer immunotherapy is determined by the characteristics of TME, which regulates inflammation and the immunosurveillance (Fukumura et al., 2018; Schaaf et al., 2018). Therefore, a strategy of reducing inflammation and increasing immunity enhances the synergistic effect on the combination immunotherapy (Chen and Mellman, 2017). It is well-known that traditional Chinese medicine (TCM) is a combination of personal medicine and combinatorial cancer therapy (Liu et al., 2015). In the past, TCM acts as an anxiliary role for cancer treatment, especially after chemotherapy or radiotherapy. Currently, the majority of patients with cancer only takes TCM as an alternative therapy to provide nutritional and psychological comfort rather than therapeutic purposes (Xu et al., 2013; Liu et al., 2015), although cancer has been treated with TCM for many years and recorded in ancient medical books.

\section{Explanations for the Mystery Surrounding Traditional Chinese Medicine}

TCM is based on a holistic view and considers the body as a complex and integrated system; therefore, its treatment has no standardization. Instead, the physician adjusted the medication and prescriptions according to different pathogenesis of patients, which can be considered as a kind of personalized medical treatment. However, sometime it is hard to give an explanation that why different diseases are treated with the same prescription (異病同治 in Mandarin/Chinese), and the same disease is treated with different prescriptions (同病異治 in Mandarin/Chinese). In addition, the most troublesome issue is scientific diagnosis because the same patient can be diagnosed by different doctors who recommend different treatments and even treated by opposite strategies (Liu et al., 2015). Another TCM mystery is its terminology. It is not described with modern scientific language and is often defined using idioms that only a trained, disciplined professional can understand. Besides, physicians cannot always explain why the treatment is effective and the mechanism of action cannot be explained in scientific terms. This communication problem persists today.

TCM mystery is further exacerbated by the current domesticated herbal cultivation practice that often produces herbs with no bioactive components. In the past, herbs were grown in the natural environment suitable for the species of herbs to obtain all the natural nutrients required to produce the therapeutic biologically active molecules. Based on this information, variations in the effectiveness of herbs from different origins and pharmaceutical companies have been observed. TCM practitioners who simply measure the weight of herbs instead of precisely measuring active ingredients coupled with patients returning to their own decoctions of drugs have contributed to the lack of standardization and scientific evidence. However, if the treatment was not effective, TCM would have been eliminated long ago, yet it has survived and enjoyed a revival in the global integrated health system. The most recent version of International Classification of Diseases (ICD-11) approved by the World Health Organization (WHO), is the first authority to include a chapter on TCM (2019). It reflects the wide-ranging impact of TCM on a global scale (Cyranoski, 2018). Further studies are needed to determine whether the international understanding and acceptance of TCM will change the field of biomedicine (Qiu, 2007).

\section{Six Strategies for Cancer Therapy by Traditional Chinese Medicine}

TCM states that people become sick because of the disequilibrium of immunity. Diseases, including cancer, are also caused by internal or external evils, or by the inability of the body to balance an internal or external stimulus (Nagi et al., 2014). It has a long history for that cancer is treated with TCM. The diagnosis and treatment of tumors were discussed in the ancient and classical literatures of Chinese medicine, such as the Yellow Emperor's Inner Canon (黃帝內經), more than 2000 years ago. The major concepts are strengthening body resistance and eliminating pathogens and treating both the manifestation and root cause. Precious heritage has laid the foundation for the innovation and development of cancer treatment with TCM (Liu et al., 2015). Here, we attempt to provide insights into the development of TCM in oncology and interpret how TCM practitioners treat cancer through six general strategies of TCM by using modern scientific language and terms based on newly discovered evidence (Table 1).

\section{FuZhengQuXie Strategy}

The first principle is the FuZhengQuXie method (扶正祛邪 in Mandarin/Chinese), which is literally translated to strengthening the resistance of the body (vital qi) and supporting healthy energy to eliminate pathogenic factors (expel the evil). It plays a central role in the TCM treatment of disease and often resonates with Chinese medicine practitioners. "Zheng" is defined as a normal qi, which is a type of healthy energy. When this righteous force is insufficient, people will get sick (Leong et al., 2015).

In this method, TCM often uses the fungi Ganoderma lucidum (Lingzhi or Reishi), Poria (Fu-Ling, Mandarin/ Chinese) and other species as drugs; the fungi contain $\beta$-glucan or polysaccharide, which is known to enhance the effect of the immune system (Driscoll et al., 2009). Unfortunately, only laboratory data are available, and evidence for the anti-cancer effects of mushrooms from clinical trials is lacking (Jiang et al., 2017). Recently, $\beta$-glucan-induced trained immunity was observed to reverse lipopolysaccharide-induced immune paralysis through metabolic reprogramming and maintaining the integrity of the tricarboxylic acid cycle (Domínguez-Andrés et al., 2019). Consistent with these findings, the metabolic rewiring of 
TABLE 1 | Traditional Chinese medicine (TCM) formula for cancer treatment.

\begin{tabular}{|c|c|c|c|c|c|}
\hline Strategy & $\begin{array}{l}\text { Name of } \\
\text { formula }\end{array}$ & Composition & Active compound & $\begin{array}{l}\text { Mechanism of } \\
\text { action }\end{array}$ & References \\
\hline \multirow[t]{2}{*}{$\begin{array}{l}\text { FuZhengQuXie (扶 } \\
\text { 正祛邪) }\end{array}$} & $\begin{array}{l}\text { Sijunzi decoction (四 } \\
\text { 君子湯) }\end{array}$ & $\begin{array}{l}\text { Panax ginseng C. A. Mey. 人參 } \\
\text { Glycyrrhiza uralensis fisch. 多甘草. } \\
\text { Poria cocos (schw.) wolf 获苓 } \\
\text { Atractylodes macrocephala koidz. } \\
\text { 白术 }\end{array}$ & $\beta$-Glucan/polysaccharide & $\begin{array}{l}\text { Activation of macrophage. } \\
\text { Anti-oxidation. Activation of } \\
\text { dendritic cells and } \\
\text { macrophages }\end{array}$ & $\begin{array}{l}\text { (Zhou et al., 2019) (Huang } \\
\text { et al., 2017) } \\
\text { (Driscoll et al., 2009; Camilli } \\
\text { et al., 2018) }\end{array}$ \\
\hline & & $\begin{array}{l}\text { Ganoderma lucidum (lingzhi or } \\
\text { reishi) 靈芝 Cordyceps sinensis } \\
\text { (berk.) sacc. 蟲草 }\end{array}$ & $\begin{array}{l}\beta \text {-Glucan/polysaccharide } \\
\text { Cordycepin }\end{array}$ & $\begin{array}{l}\text { Activation of NK cells and } \\
\text { macrophages. Anti- } \\
\text { inflammation }\end{array}$ & $\begin{array}{l}\text { (Driscoll et al., 2009; Camilli } \\
\text { et al., 2018) (Qin et al., 2019) }\end{array}$ \\
\hline \multirow[t]{3}{*}{$\begin{array}{l}\text { QingReJieDu (清 } \\
\text { 熱解毒) }\end{array}$} & $\begin{array}{l}\text { SanHuangXieXin } \\
\text { decoction (三黃瀉 } \\
\text { 心湯) }\end{array}$ & $\begin{array}{l}\text { Rheum palmatum, L.大黃 Coptis } \\
\text { chinensis franch 黃連. Scutellaria } \\
\text { baicalensis Georgi黃芩 }\end{array}$ & $\begin{array}{l}\text { Berberine Pheophorbide } \\
\text { Wogonin }\end{array}$ & $\begin{array}{l}\text { Anti-inflammation. Anti- } \\
\text { angiogenesis. Pro- } \\
\text { apoptosis. Induction of } \\
\text { apoptosis/anti-inflammation }\end{array}$ & $\begin{array}{l}\text { (Cheng et al., 2008) } \\
\text { (Wang et al., 2015c) (Chan } \\
\text { et al., 2006) (Chen et al., } \\
\text { 2013; Xiao et al., 2015) }\end{array}$ \\
\hline & $\begin{array}{l}\text { Huanglian jiedu } \\
\text { decoction (黃連解 } \\
\text { 毒湯) }\end{array}$ & $\begin{array}{l}\text { Coptis chinensis Franch黃連 } \\
\text { Phellodendron chinense C. K. } \\
\text { Schneid.黃柏. Scutellaria } \\
\text { baicalensis Georgi黃芩. Gardenia } \\
\text { jasminoides J.Ellis 柧子 }\end{array}$ & $\begin{array}{l}\text { Berberine Pheophorbide } \\
\text { Wogonin }\end{array}$ & $\begin{array}{l}\text { Anti-inflammation. Pro- } \\
\text { apoptosis. Induction of } \\
\text { apoptosis/anti-inflammation. } \\
\text { Anti-proliferation }\end{array}$ & $\begin{array}{l}\text { (Huang et al., 2020) } \\
\text { (Chan et al., 2006) (Chen } \\
\text { et al., 2013; Xiao et al., 2015) } \\
\text { (Wang et al., 2015b) }\end{array}$ \\
\hline & & Cruciferous vegetables & $\begin{array}{l}\text { Sulforaphane Indole-3- } \\
\text { carbinol }\end{array}$ & Anti-oxidation & $\begin{array}{l}\text { (Traka et al., 2014) (Metidji } \\
\text { et al., 2018) }\end{array}$ \\
\hline \multirow[t]{2}{*}{$\begin{array}{l}\text { HuoXueHuaYu (活 } \\
\text { 血化瘀 }\end{array}$} & $\begin{array}{l}\text { Didang decoction (抵 } \\
\text { 當湯 }\end{array}$ & $\begin{array}{l}\text { Rheum palmatum, L.大黃. Prunus } \\
\text { persica (L.) batsch 桃仁. Hirudo } \\
\text { nipponica whitman 水蛭. Tabanus } \\
\text { bivittatus matsumura 虻蟲 }\end{array}$ & Amygdalin Hirudin & $\begin{array}{l}\text { Anti-inflammation anti- } \\
\text { thrombosis }\end{array}$ & $\begin{array}{l}\text { (Lin and Lin, 2011) } \\
\text { (Wildenrath, 1995) }\end{array}$ \\
\hline & & $\begin{array}{l}\text { Salvia miltiorrhiza bunge (danshen) } \\
\text { 丹參. Ophiocordyceps sinensis 冬 } \\
\text { 蟲夏草 }\end{array}$ & $\begin{array}{l}\text { Salvianic acid (danshensu) } \\
\text { Cordycepin }\end{array}$ & $\begin{array}{l}\text { Anti-inflammation anti- } \\
\text { angiogenesis anti- } \\
\text { thrombosis/vasodilatation. } \\
\text { Anti-angiogenesis }\end{array}$ & $\begin{array}{l}\text { (Zhang et al., 2010; Zhang } \\
\text { et al., 2018) (Li et al., 2015) } \\
\text { (Liu et al., 2020) }\end{array}$ \\
\hline \multirow[t]{2}{*}{$\begin{array}{l}\text { RuanJianSanJie } \\
\text { (軟堅散結) }\end{array}$} & XiaoLuoWan (消瘰丸) & $\begin{array}{l}\text { Scrophularia ningpoensis hemsl. 玄 } \\
\text { 參. Ostrea gigas thunberg 牡蠣. } \\
\text { Fritillaria thunbergii miq. 浙貝母. } \\
\text { Sargassum pallidum 海藻 }\end{array}$ & Calcium Verticine & $\begin{array}{l}\text { Anti-proliferation. Anti- } \\
\text { inflammation. Anti- } \\
\text { nociception }\end{array}$ & $\begin{array}{l}\text { (Chen et al., 2016b) (Xu et al., } \\
\text { 2011; Wang et al., 2015a) }\end{array}$ \\
\hline & & $\begin{array}{l}\text { Carapax trionycis (biejia) 鰲甲. } \\
\text { Trionyx sinensis wiegmann. 中華鰵 } \\
\text { bovine tracheal cartilage (BTC) }\end{array}$ & CT6 & $\begin{array}{l}\text { Inhibition of TGF- } \beta 1 \text { and anti- } \\
\text { fibrosis. Up-regulation of } \\
\text { CREB-p and anti-fibrosis }\end{array}$ & $\begin{array}{l}\text { (Hu et al., 2013; Hu et al., } \\
\text { 2017) (Tan et al., } \\
\text { 2006)'(Prudden, 1985) }\end{array}$ \\
\hline $\begin{array}{l}\text { HuaTanQuShi (化 } \\
\text { 痰祛濕) }\end{array}$ & $\begin{array}{l}\text { ErChen decoction (二 } \\
\text { 陳湯) }\end{array}$ & $\begin{array}{l}\text { Pinelliae ternata (thunb.) makino, 半 } \\
\text { 夏. Citrus reticulata blanco 陳皮. } \\
\text { Poria cocos (schw.) wolf 获苓. } \\
\text { Glycyrrhiza uralensis fisch. 多甘草 }\end{array}$ & $\begin{array}{l}\text { Ephedrine, } \beta \text {-glucan } \\
\text { Diosmin } \beta \text {-Glucan/ } \\
\text { polysaccharide }\end{array}$ & $\begin{array}{l}\text { Phlegm-eliminating, anti- } \\
\text { inflammatory, and anti- } \\
\text { metabolic syndrome effects }\end{array}$ & $\begin{array}{l}\text { (Ji et al., 2014; Xiu et al., 2015) } \\
\text { (Vafa et al., 2019) (Driscoll } \\
\text { et al., 2009; Camilli et al., } \\
\text { 2018) }\end{array}$ \\
\hline $\begin{array}{l}\text { YangXinAnShen } \\
\text { (養心安神) }\end{array}$ & $\begin{array}{l}\text { Suanzaoren } \\
\text { decoction (酸菓仁湯) }\end{array}$ & $\begin{array}{l}\text { Ziziphus jujuba mill. Var. spinosa } \\
\text { (bunge) 酸妻仁. Poria cocos (Schw) } \\
\text { 获苓. Ligusticum chuanxiong 川芎. } \\
\text { Glycyrrhiza uralensis fisch. 甘草 }\end{array}$ & $\begin{array}{l}\text { Acidic polysaccharides } \\
\text { Jujuboside A } \\
\text { Chuanxiongzine/ } \\
\text { tetramethyl pyrazine }\end{array}$ & $\begin{array}{l}\text { Activation of immune cells. } \\
\text { Hypnotic Vasodilatation }\end{array}$ & $\begin{array}{l}\text { (Zou et al., 2018) (Cao et al., } \\
\text { 2010) (Xu et al., 2018) }\end{array}$ \\
\hline
\end{tabular}

TCM, traditional chinese medicine.

immune cells in the TME might enhance antitumor immunity (Li et al., 2019).

$\beta$-Glucan has been used as a potential cancer immunotherapy because it targets macrophages (Camilli et al., 2018; Cassetta and Kitamura, 2018; Domínguez-Andrés et al., 2019; Li et al., 2019) and NK cells (Chiba et al., 2014; Okabe and Medzhitov, 2014). Interestingly, $\beta$-glucan might restore NK cells in patients receiving treatment for cancer. $\beta$-Glucan also enhances hematopoietic recovery after bone marrow injury (Cramer et al., 2006) and modulates the expansion of myelopoiesis after chemotherapy (Mitroulis et al., 2018). The immune system should no longer only be viewed with the traditional concept of fighting pathogens, but also maintaining tissue and whole-body homeostasis (Rankin and Artis, 2018). $\beta$-Glucan induced trained immunity (innate immune memory) generated via pathogen recognition receptors (PRRs) may be the mechanism underlying the effects of FuZhengQuXie as a TCM (Rubartelli and Lotze, 2007; Nagi et al., 2014).

\section{QingReJieDu Strategy}

The second principle is the QingRejieDu method (清熱解毒 in Mandarin/Chinese), which is defined as clearing away heat and toxic substances. The source of Heat (HuoQi) that leads to toxicity is considered to be oxidative stress and inflammation. It induces damage at the cellular level in various tissues and organs, resulting in cardiovascular disease, hepatic injury, autoimmunity, lung disease, disorders of the reproductive system, retinopathy, neurotoxicity, neurodegenerative diseases, and carcinogenesis (Kohen and Nyska, 2002). 
The QingReJieDu method is one of cancer treatment principles in TCM that balances oxidative stress and detoxification, including the regulation of energy metabolism and reduction in the levels of harmful metabolites. Modulation of oxidative stress and redox signaling is critical to regulate the equilibrium of cancer stem cell state and metastasis (Luo et al., 2018). The tumor cells secrete inflammatory factors that promote the inflammation in the tumor microenvironment; inflammation also inhibits immune response in cancer patients (Coussens and Werb, 2002; Kuo et al., 2020). The chinese pactitioners used QingReJieDu method to treat cancer when there is "Heat evil" or "Heat toxin" in the process of pathological mechanism. There are two commonly used TCM prescriptions/formula, SanHuangXieXin decoction (三黃瀉心湯) and Huanglian Jiedu decoction (黃連解毒湯), which were used to achieve the heat-clearing and detoxifying treatment (Table 1). The formula named SanHuangXieXin decoction is made up of three herbs, which are Coptis chinensis Franch, Scutellaria baicalensis Georgi, and Rheum palmatum L. Both decoctions are comprised of Coptidis chinensis and Scutellaria baicalensis. Berberine in Coptidis chinensis can suppress inflammation in cancer (Cheng et al., 2008; Huang et al., 2020). Pheophorbide in Scutellaria baicalensis is able to induce apoptosis of tumor cells (Chan et al., 2006). Wogonin in Scutellaria baicalensis has anti-inflammatory activity and can induce apoptosis of tumor cells (Chen et al., 2013; Xiao et al., 2015). In addition, a previous report indicated that Huanglian Jiedu decoction targets eukaryotic elongation factor 2 to attenuate cancer progression of hepatocellular carcinoma (Wang et al., 2015b).

On the other hand, cauliflower and broccoli are considered by TCM to belong to a type of food known as GanHanYangYin (甘 寒養陰 in Mandarin/Chinese). These vegetables gently cool the body and maintain the nutrition-based repair system. Based on the results of recent studies on cruciferous vegetables, their functions are attributed to a substance called sulforaphane (SFN). It increases the activity of the phase II enzyme system by promoting Nrf2 nuclear translocation to induce the expression of genes related to detoxification and the inhibition of oxidation stress (Traka et al., 2014). Additionally, Nrf2 regulates the expression of mitochondrial enzymes to restore cellular vitality (Holmström et al., 2016). In addition, indole-3-carbinol (I3C), a compound present in cruciferous vegetables as a natural aryl hydrocarbon receptor (AHR) ligand, prevents inflammatory damage by maintaining intestinal stem cell homeostasis and barrier integrity (Metidji et al., 2018). Novel findings also suggest the reactivation of PTEN tumor suppressor through I3C-mediated WWP1 inhibition as a potential strategy for cancer treatment (Lee and Chen, 2019). TCM herbal extracts containing polyphenolic compounds, such as ellagitannins (ETs) and ellagic acid (EA), which enhance the barrier integrity by regulating the levels of a microbial metabolite through the Nrf2 pathway (Ito, 2011; Singh et al., 2019), thus providing the clue of QingReJieDu.

\section{HuoXueHuaYu Strategy}

The third principle is the HuoXueHuaYu method (活血化瘀 in Mandarin/Chinese), which is defined as invigorating blood circulation and eliminating stasis. Cancer cells, fibroblasts, immune cells, and vasculature endothelial cells consist of the tumor microenvironment (TME). Their interaction in the TME determines the property and nature of cancer tissues through secretion of cytokines and other substances throughout the environment, which is crucial to tumor progression and metastasis (Kuo et al., 2020). Cancer tissues in a microenvironment depend on angiogenesis to supply their need for nutrients and oxygen; vessel formation after angiogenesis also becomes a route to metastasis. However, the network of tumor-associated blood vessels is chaotic and leaky, which increases interstitial fluid (IFP) pressure and difficulty in transportation. The collapsed vessels result in tumor regions that are hypoxic; moreover, the glycolytic nature of the hypoxic tumor cell acidifies the $\mathrm{pH}$ in the TME. The hypoxic and acidic TME that facilitates the genetic and epigenetic alterations that enhance their inflammation and aggressiveness (Schaaf et al., 2018). This highly aberrant angiogenesis contributes to maintain the immunosuppressive TME and causes cancer cells to escape the immunosurveillance and resist immunotherapy (Fukumura et al., 2018). Thus a strategy of vascular normalization was used to reduce excess angiogenesis and increase immune cells infiltration that further enhance the synergistic effect on the combination immunotherapy (Huang et al., 2012; Sung et al., 2019).

In addition, the difficulty in vessel transportation contributes the cancer-platelet interaction, platelet activation, the coagulation, and thromboembolism, which protects cancer cells from shear stress and immunological attack and facilitates to form a new metastasis (Lu et al., 2019). From TCM's point of view, the origin of tumorigenesis is mediated by TanYuQiZu (痰瘀氣阻 in Mandarin/Chinese). It is explained as the difficulty in vessel transportation causes the hypoxic and acidic TME (metabolic waste accumulation) to trigger the inflammation and immunosuppression (Chung et al., 2013; Jain, 2014), which is exacerbated by metabolic reprogramming into the glycolytic nature of cancer cells. It is a promising approach that if the treatment can inhibit extensive angiogenesis and make vascular normalization; at the same time, the treatment can allow for eliminating thrombosis and improve inflammatory TME, which promotes infiltration of immune cells and activates $\mathrm{CD}^{+} \mathrm{T}$ cells. TCM prescriptions containing pharmacological effects of components have an effect on cancers through anti-angiogenesis, anti-inflammation, and anti-thrombosis, and invigorating blood circulation. For example, amygdalin in Didang decoction (抵當湯) has a role in antiinflammation, and both Salvianic acid (Danshensu) in Salvia miltiorrhiza Bge.(Danshen) and Cordycepin in Cordyceps sinensis have anti-inflammation and anti-angiogenesis activities (Zhang et al., 2010; Zhang et al., 2018; Liu et al., 2020). On the other hand Hirudin in Hirudo nipponica (Didang decoction) has antithrombosis activitity (Wildenrath, 1995) (Table 1). Since cancer immunotherapy plays a major role on the stage of cancer therapy and several therapeutic approaches have targeted the hypoxic TME to improve the clinical outcome of antiangiogenic therapy (Rapisarda and Melillo, 2012; Sennino and McDonald, 2012), TCM will be expected to enhance vascular normalization as a strategy to increase immune cell infiltration by vessel and further enhance the combination immunotherapy. 


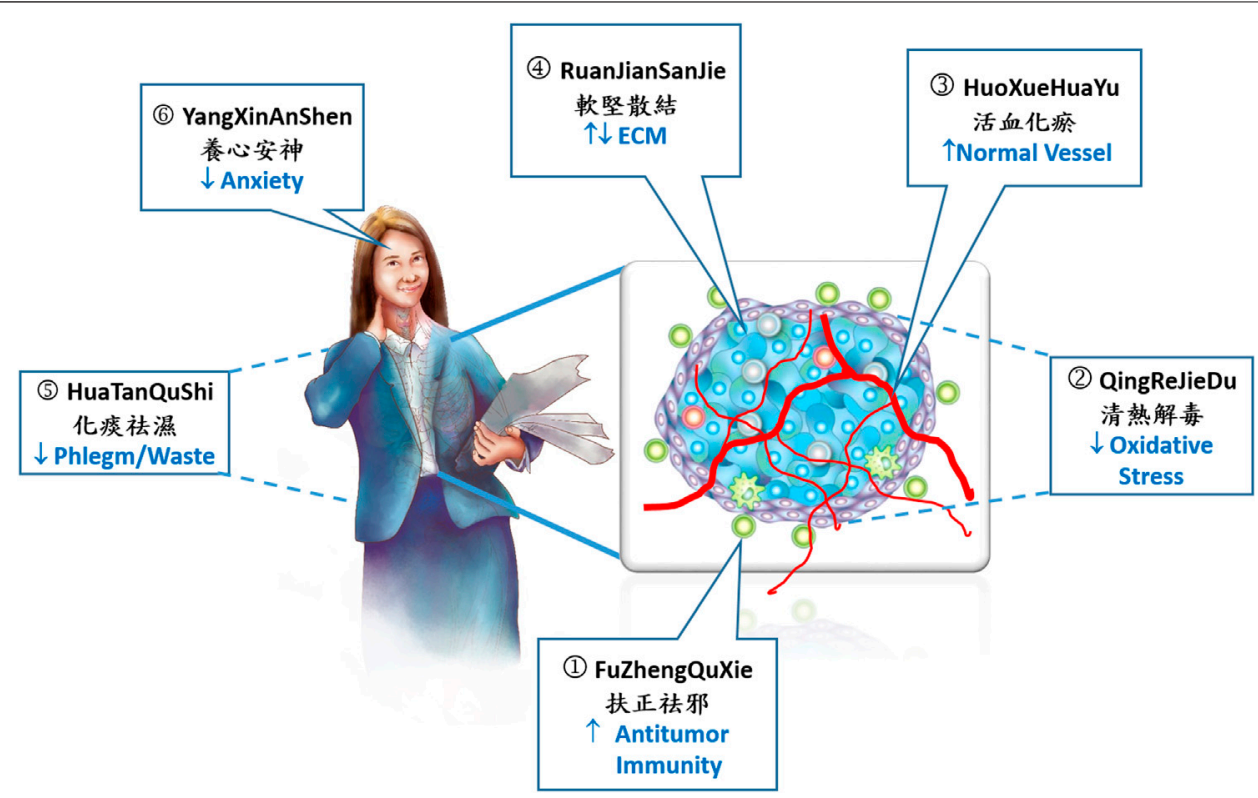

FIGURE 1 | Six strategies for cancer therapy by TCM. Traditional Chinese medicine (TCM) utilizes six principles of homeostasis and balance to treat cancer. 1) Equilibrium of immunity plays a central role in the cancer treatment by TCM. 2) TCM balances detoxification and reduces oxidative stress and inflammation. 3) TCM utilizes a strategy of vascular normalization to reduce excess angiogenesis and increase immune cells infiltration that further enhance immunotherapy. 4) TCM regulates extracellular matrix (ECM) in the tumor microenvironment. 5) Restoration of metabolic imbalance and stimulation of phlegm-eliminating and anti-inflammatory activity by TCM. 6) Reduction of psychological stress and relief of anxiety by TCM decoction. In the tumor tissue: Blue irregular cells represent tumor cells. Green and blue circle cells represent infiltrated immune cells, T lymphocyte, neutrophil, and macrophage. Red line represents blood vessels. Purple cells represent stromal cells and ECM.

\section{RuanJianSanJie Strategy}

The fourth principle is the RuanJianSanJie method (軟堅散結 in Mandarin/Chinese), which means softening and resolving hard masses and dispersing the accumulation of a pathogenic texture. Based on clinical trials, TCM prescriptions containing extracellular matrix (ECM) components exert a curative effect on hyperplasia or tumors. Using this method, TCM practitioners used seaweed, Carapax trionycis (Biejia), and even exotic animal materials in the ancient period. Recently the TME and its cellular matrix were shown to play important roles in cancer treatment (Pearce et al., 2018; Tlsty and Gascard, 2019). This method could be translated to reorganize the ECM of the TME.

Currently, invasive tumor margins with high stromal TGF $\beta$ activity are recognized to be associated with tumors that do not contain T cells. TGF $\beta$ signaling has been a therapeutic target (Mariathasan et al., 2018; Tauriello et al., 2018). Galunisertib, a TGF $\beta$ inhibitor in development by Eli Lilly is in a phase II trial for the treatment of hepatocellular carcinoma (Harjes, 2018). Carapax trionycis (Biejia), a traditional Chinese medicine originating from the shell of Trionyx sinensis Wiegmann, was also used as a candidate treatment for liver fibrosis. Its active ingredients interfere with TGF- $\beta 1$ signaling by decreasing Smad three phosphorylation in cultured hepatic stellate cells (HSC), which are the main ECM-producing cells (Hu et al., 2013).

Many studies have focused on cartilage components with antiangiogenesis activity in cancer therapy in the past few years (Moses et al., 1990; Patra and Sandell, 2012; Foradori et al., 2014). Recently, sulfated hyaluronans (sHA), a component of the ECM, were reported to decrease TGF- $\beta 1$ bioactivity in fibroblasts (Koehler et al., 2017). ECM components from animals, i.e., cartilage, with abundant glycosaminoglycans possess antiangiogenesis activity and other functions. Coincidentally, the FDA-approved drug Catrix ${ }^{\circledR}$ derived from bovine tracheal cartilage (BTC) has been used to heal wounds (Prudden et al., 1964) and treat cancer (Prudden et al., 1964), similar to Carapax Trionycis (Biejia) in TCM. Additional investigations of this type of crosstalk will reveal how ECM regulates the TME.

\section{HuaTanQuShi Strategy}

The fifth principle is the HuaTanQuShi method (化痰祛濕 in Mandarin/Chinese), which is defined as eliminating water and waste through metabolism. Metabolic disease is a complex cluster of metabolic imbalance, including typically obesity, insulin resistance, dyslipidemia and hypertension, at increase risk of type 2 diabetes mellitus, atherosclerosis and cardiovascular events. Cancer is also a complex disease of metabolic imbalance or reprogramming (Hay, 2016). Many studies have shown an association between metabolic disease and inflammation that is associated with higher risk of incidence for cancer (Xing et al., 2015; Saltiel and Olefsky, 2017; Wang et al., 2019). The main pharmacological effects of WenDan decoction (溫膽湯) and ErChen decoction (二陳湯) on cancer may consist in the regulation of lipid and glucose metabolisms as well as immunomodulatory function (Chen et al., 2016a). Both formula are comprised of Pinellia Ternata and Citrus reticulata. The genus Pinellia had improved clinical therapeutic effects for eliminating 
phlegm, anti-inflammation, and lowering blood pressure, glucose and cholesterol levels (Ji et al., 2014; Xiu et al., 2015). Diosmin in Citrus reticulata has a role in phlegm-eliminating, anti-inflammatory, and anti-metabolic syndrome effects (Vafa et al., 2019) (Table 1).

\section{YangXinAnShen Strategy}

The sixth principle is the YangXinAnShen method (養心安神 in Mandarin/Chinese), which is defined as tranquilizing mind. Many studies have shown an association between psychological stress and cancer progression and metastasis (Powell et al., 2013; Shin et al., 2016). For instance, depression is associated with higher risk of mortality for patients with cancer (Pinquart and Duberstein, 2010; Lin et al., 2018). It is reasonable that reducing pressure, tranquilizing mind, and relief of anxiety in cancer patients will help control tumor progression. It is wellestablished that adrenergic neurons largely contribute to tumor growth and progression (Magnon et al., 2013). An exciting study showed that carvedilol, an inhibitor of adrenergic signaling, will lighten a way to combat the tumor-driven formation of adrenergic neurons in head and neck cancer (Amit et al., 2020). A number of clinical trials have shown that patients with cancer benefit from TCM as an adjunct to conventional treatment (Liu et al., 2015; Liao et al., 2017). The fatigue and anxiety in patients with prostate cancer can be improved by the treatment of Kamikihitou (加味歸脾湯) by restoring the balance of the autonomic nervous system (Tamada et al., 2018). The retrospective cohort study showed that the treatment of Suanzaoren decoction (酸霖仁湯) (Cao et al., 2010) and TianWangBuXinDan (天 王補心丹) improved overall mortality and survival in prostate cancer patients with depression (Lin et al., 2019) (Table 1).

\section{CONCLUSION AND PERSPECTIVES}

A better understanding of the principles of TCM based on the most recent evidence of scientific research will assist in the development of new cancer treatment. Here, we present the six major strategies for treating cancer used in TCM (Figure 1), and each strategy usually covers and targets various modern hallmarks of cancer (Hanahan and Weinberg, 2011), which reveals a combinatorial strategy of cancer therapy. This trend meets the concept of the tumor microenvironment and the rise of cancer immunotherapy, which represent a revolutionary change in the cancer treatment.

The main principle and philosophy of TCM is a holistic treatment, which is quite different from the Western medicine. Actually, TCM is also a combination of personal medicine and combinatorial cancer immunotherapy. After the diagnosis of inspecting, smelling, inquiring/listening, and taking palpation of the patient, Chinese medicine doctor then will distinguish the pattern of syndrome, sum up a pathological mechanism, and propose a prescription. To obtain an accurate prescription, Chinese medicine doctor may modify a traditional formulation by adding or subtracting herbs according to each individual patient. Of course, a TCM formulation is a kind of combination therapy. Therefore, the six strategies for cancer therapy mentioned in our work can be assortedly used in the treatment of cancer patients because cancer is a kind of complicated systematic disease. For example, the famous prescription of Xiao-Chai-Hu decoction (小柴胡湯) contains three strategies mentioned in the formulation for cancer treatment, including FuZhengQuXie, QingReJieDu, and HuaTanQuShi strategy. Xiao-Chai-Hu decoction contains ginseng radix and Glycyrrhizae radix that strengthen the resistance of the body (FuZhengQuXie), scutellaria baicalensis that clears away heat and toxic substances (QingReJieDu), and Pinelliae ternata that eliminates water and waste through metabolism (HuaTanQuShi). Accordingly, in recent years, researchers were starting to study TCM using the approach of system biology. They uncovered the interactive mechanisms of TCM formulas by using chemomic, transcriptomic, and/or proteomic approaches in relevant research (Lin et al., 2015; Chen et al., 2016a; Yin et al., 2020), which should be crucial for interpretation of TCM development. In the future, more studies on TCM formulas using systematic approaches are necessary to understand the interactive mechanisms of the formulas, which can be used directly in personalization medicine and the combination therapy of cancer patients with other therapies and immunotherapy in a holistic way.

In this review article, we have provided a new perspective knowledge of TCM in cancer therapy. Combined with the ancient wisdom of TCM and the language of modern science, we will look forward to finding new solutions to control cancer as a chronic disease with improved efficacy. Eventually, we hope that TCM is not just practical experiences, but a scientific medicine and holistic philosophy of therapy, which is quietly waiting and worthy for us to discover the truth and wisdom in the TCM.

\section{DATA AVAILABILITY STATEMENT}

The original contributions presented in the study are included in the article, further inquiries can be directed to the corresponding authors.

\section{AUTHOR CONTRIBUTIONS}

S-HL, P-SC, and AY-LL conceived the project. C-CH, Y-TH, M$\mathrm{YL}, \mathrm{W}-\mathrm{HL}$, and Y-CL provided discussion and suggestions to the manuscript. S-HL, P-SC, and AY-LL wrote the manuscript with input from all authors.

\section{FUNDING}

This work was partly supported by grants from the Ministry of Science and Technology (MOST105-2628-B-400-003-MY3, MOST105-2627-M-400-002, MOST108-2320-B-400-008-MY3) and National Health Research Institutes (109A1-CA-PP-07), Taiwan to AY-LL.

\section{ACKNOWLEDGMENTS}

The authors are grateful to Miss Ingrid Kuo for creating the illustrations used in the manuscript. 


\section{REFERENCES}

Allison, J. P., Barrueto, L., Caminero, F., Cash, L., Makris, C., Lamichhane, P., et al. (2020). Resistance to checkpoint inhibition in cancer immunotherapy. Canc. Discov. 13 (3), 100738. doi:10.1158/2159-8290.cd-18-0367

Amit, M., Takahashi, H., Dragomir, M. P., Lindemann, A., Gleber-Netto, F. O., Pickering, C. R., et al. (2020). Loss of p53 drives neuron reprogramming in head and neck cancer. Nature 578 (7795), 449-454. doi:10.1038/s41586-020-1996-3

Camilli, G., Tabouret, G., and Quintin, J. (2018). The complexity of fungal $\beta$-glucan in health and disease: effects on the mononuclear phagocyte system. Front. Immunol. 9, 673. doi:10.3389/fimmu.2018.00673

Cao, J. X., Zhang, Q. Y., Cui, S. Y., Cui, X. Y., Zhang, J., Zhang, Y. H., et al. (2010). Hypnotic effect of jujubosides from semen ziziphi spinosae. J. Ethnopharmacol. 130 (1), 163-166. doi:10.1016/j.jep.2010.03.023

Cassetta, L., and Kitamura, T. (2018). Macrophage targeting: opening new possibilities for cancer immunotherapy. Immunology 155 (3), 285-293. doi:10.1111/imm.12976

Chan, J. Y., Tang, P. M., Hon, P. M., Au, S. W., Tsui, S. K., Waye, M. M., et al. (2006). Pheophorbide a, a major antitumor component purified from scutellaria barbata, induces apoptosis in human hepatocellular carcinoma cells. Planta Med. 72 (1), 28-33. doi:10.1055/s-2005-873149

Chen, D. S., and Mellman, I. (2017). Elements of cancer immunity and the cancerimmune set point. Nature 541 (7637), 321-330. doi:10.1038/nature21349

Chen, M., Yang, F., Yang, X., Lai, X., and Gao, Y. (2016a). Systematic understanding of mechanisms of a chinese herbal formula in treatment of metabolic syndrome by an integrated pharmacology approach. Int. J. Mol. Sci. 17 (12). doi:10.3390/ijms 17122114

Chen, Y., Jiang, Y., Liao, L., Zhu, X., Tang, S., Yang, Q., et al. (2016b). Inhibition of $4 \mathrm{NQO}-$ induced oral carcinogenesis by dietary oyster shell calcium. Integr. Cancer Ther. 15 (1), 96-101. doi:10.1177/1534735415596572

Chen, X. M., Bai, Y., Zhong, Y. J., Xie, X. L., Long, H. W., Yang, Y. Y., et al. (2013). Wogonin has multiple anti-cancer effects by regulating c-Myc/SKP2/Fbw7 $\alpha$ and HDAC1/HDAC2 pathways and inducing apoptosis in human lung adenocarcinoma cell line A549. PLoS One 8 (11), e79201. doi:10.1371/ journal.pone.0079201

Cheng, W. Y., Wu, S. L., Hsiang, C. Y., Li, C. C., Lai, T. Y., Lo, H. Y., et al. (2008). Relationship between san-huang-xie-xin-tang and its herbal components on the gene expression profiles in HepG2 cells. Am. J. Chin. Med. 36 (4), 783-797. doi:10.1142/s0192415x08006235

Chiba, S., Ikushima, H., Ueki, H., Yanai, H., Kimura, Y., Hangai, S., et al. (2014). Recognition of tumor cells by Dectin-1 orchestrates innate immune cells for anti-tumor responses. Elife 3, e04177. doi:10.7554/eLife.04177

Chung, A. S., Wu, X., Zhuang, G., Ngu, H., Kasman, I., Zhang, J., et al. (2013). An interleukin-17-mediated paracrine network promotes tumor resistance to antiangiogenic therapy. Nat. Med. 19 (9), 1114-1123. doi:10.1038/nm.3291

Coussens, L. M., and Werb, Z. (2002). Inflammation and cancer. Nature 420 (6917), 860-867. doi:10.1038/nature01322

Cramer, D. E., Allendorf, D. J., Baran, J. T., Hansen, R., Marroquin, J., Li, B., et al. (2006). Beta-glucan enhances complement-mediated hematopoietic recovery after bone marrow injury. Blood 107 (2), 835-840. doi:10.1182/blood-2005-072705

Cyranoski, D. (2018). Why Chinese medicine is heading for clinics around the world. Nature 561 (7724), 448-450. doi:10.1038/d41586-018-06782-7

Domínguez-Andrés, J., Novakovic, B., Li, Y., Scicluna, B. P., Gresnigt, M. S., Arts, R. J. W., et al. (2019). The itaconate pathway is a central regulatory node linking innate immune tolerance and trained immunity. Cell Metabol 29 (1), 211-220.e215. doi:10.1016/j.cmet.2018.09.003

Driscoll, M., Hansen, R., Ding, C., Cramer, D. E., and Yan, J. (2009). Therapeutic potential of various beta-glucan sources in conjunction with anti-tumor monoclonal antibody in cancer therapy. Cancer Biol. Ther. 8 (3), 218-225. doi:10.4161/cbt.8.3.7337

Foradori, M. J., Chen, Q., Fernandez, C. A., Harper, J., Li, X., Tsang, P. C., et al. (2014). Matrilin-1 is an inhibitor of neovascularization. J. Biol. Chem. 289 (20), 14301-14309. doi:10.1074/jbc.M113.529982

Fukumura, D., Kloepper, J., Amoozgar, Z., Duda, D. G., and Jain, R. K. (2018). Enhancing cancer immunotherapy using antiangiogenics: opportunities and challenges. Nat. Rev. Clin. Oncol. 15 (5), 325-340. doi:10.1038/nrclinonc.2018.2
Gatenby, R. A. (2009). A change of strategy in the war on cancer. Nature 459 (7246), 508-509. doi:10.1038/459508a

Hanahan, D., and Weinberg, R. A. (2011). Hallmarks of cancer: the next generation. Cell 144 (5), 646-674. doi:10.1016/j.cell.2011.02.013

Harjes, U. (2018). Immunotherapy: tear down this wall. Nat. Rev. Immunol. 18 (4), 221. doi:10.1038/nri.2018.20

Hay, N. (2016). Reprogramming glucose metabolism in cancer: can it be exploited for cancer therapy?. Nat. Rev. Cancer 16 (10), 635-649. doi:10. 1038/nrc.2016.77

Hoadley, K. A., Yau, C., Hinoue, T., Wolf, D. M., Lazar, A. J., Drill, E., et al. (2018). Cell-of-Origin patterns dominate the molecular classification of 10,000 tumors from 33 types of cancer. Cell 173 (2), 291-304.e296. doi:10.1016/j.cell.2018. 03.022

Holmström, K. M., Kostov, R. V., and Dinkova-Kostova, A. T. (2016). The multifaceted role of Nrf2 in mitochondrial function. Curr. Opin. Toxicol. 1, 80-91. doi:10.1016/j.cotox.2016.10.002

Hu, C. L., Peng, X. Z., Tang, Y. P., and Liu, Y. W. (2013). Synthesis of peptides of Carapax Trionycis and their inhibitory effects on TGF- $\beta 1$-induced hepatic stellate cells. Drug Discov. Ther. 7 (6), 248-253. doi:10.5582/ddt.2013.v7. 6.248

Hu, Z., You, P., Xiong, S., Gao, J., Tang, Y., Ye, X., et al. (2017). Carapax Trionycis extracts inhibit fibrogenesis of activated hepatic stellate cells via TGF- $\beta 1 / \mathrm{Smad}$ and NFkB signaling. Biomed. Pharmacother. 95, 11-17. doi:10.1016/j.biopha. 2017.08.011

Huang, C., Zhu, Z., Cao, X., Chen, X., Fu, Y., Chen, Z., et al. (2017). A pectic polysaccharide from sijunzi decoction promotes the antioxidant defenses of SW480 cells. Molecules 22 (8), 1341. doi:10.3748/wjg.v24.i26.2867

Huang, J., Guo, W., Cheung, F., Tan, H. Y., Wang, N., and Feng, Y. (2020). Integrating network pharmacology and experimental models to investigate the efficacy of Coptidis and scutellaria containing huanglian Jiedu decoction on hepatocellular carcinoma. Am. J. Chin. Med. 48 (1), 161-182. doi:10.1155/2018/ 6707850

Huang, Y., Yuan, J., Righi, E., Kamoun, W. S., Ancukiewicz, M., Nezivar, J., et al. (2012). Vascular normalizing doses of antiangiogenic treatment reprogram the immunosuppressive tumor microenvironment and enhance immunotherapy. Proc. Natl. Acad. Sci. U.S.A. 109 (43), 17561-17566. doi:10.1073/pnas. 1215397109

Ito, H. (2011). Metabolites of the ellagitannin geraniin and their antioxidant activities. Planta Med. 77 (11), 1110-1115. doi:10.1055/s-0030-1270749

Jain, R. K. (2014). Antiangiogenesis strategies revisited: from starving tumors to alleviating hypoxia. Cancer Cell 26 (5), 605-622. doi:10.1016/j.ccell.2014.10.006

Ji, X., Huang, B., Wang, G., and Zhang, C. (2014). The ethnobotanical, phytochemical and pharmacological profile of the genus pinellia. Fitoterapia 93, 1-17. doi:10.1016/j.fitote.2013.12.010

Jiang, Y., Chang, Y., Liu, Y., Zhang, M., Luo, H., Hao, C., et al. (2017). Overview of Ganoderma sinense polysaccharide-an adjunctive drug used during concurrent chemo/radiation therapy for cancer treatment in china. Biomed. Pharmacother 96, 865-870. doi:10.1016/j.biopha.2017.09.060

Jiménez-Sánchez, A., Memon, D., Pourpe, S., Veeraraghavan, H., Li, Y., Vargas, H. A., et al. (2017). Heterogeneous tumor-immune microenvironments among differentially growing metastases in an ovarian cancer patient. Cell 170 (5), 927-938.e920. doi:10.1016/j.cell.2017.07.025

Koehler, L., Samsonov, S., Rother, S., Vogel, S., Köhling, S., Moeller, S., et al. (2017). Sulfated hyaluronan derivatives modulate TGF- $\beta 1$ :receptor complex formation: possible consequences for TGF- $\beta 1$ signaling. Sci. Rep. 7 (1), 1210. doi:10.1038/ s41598-017-01264-8

Kohen, R., and Nyska, A. (2002). Oxidation of biological systems: oxidative stress phenomena, antioxidants, redox reactions, and methods for their quantification. Toxicol. Pathol. 30 (6), 620-650. doi:10.1080/ 01926230290166724

Kuo, C. L., Chou, H. Y., Chiu, Y. C., Cheng, A. N., Fan, C. C., Chang, Y. N., et al. (2020). Mitochondrial oxidative stress by Lon-PYCR1 maintains an immunosuppressive tumor microenvironment that promotes cancer progression and metastasis. Cancer Lett. 474, 138-150. doi:10.1016/j.canlet. 2020.01.019

Lee, Y. R., and Chen, M. (2019). Reactivation of PTEN tumor suppressor for cancer treatment through inhibition of a MYC-WWP1 inhibitory pathway. Science 364 (6441), eaau0159. doi:10.1126/science.aau0159 
Leong, P. K., Wong, H. S., Chen, J., and Ko, K. M. (2015). Yang/Qi invigoration: an herbal therapy for chronic fatigue syndrome with yang deficiency?. Evid. Based. Complement. Alternat. Med. 2015, 945901. doi:10.1155/2015/945901

Li, R. W., Yang, C., Shan, L., Zhang, Z., Wang, Y., Kwan, Y. W., et al. (2015). Relaxation effect of a novel Danshensu/tetramethylpyrazine derivative on rat mesenteric arteries. Eur. J. Pharmacol. 761, 153-160. doi:10.1016/j.ejphar.2015. 04.041

Li, X., Wenes, M., Romero, P., Huang, S. C., Fendt, S. M., and Ho, P. C. (2019). Navigating metabolic pathways to enhance antitumour immunity and immunotherapy. Nat. Rev. Clin. Oncol. 16 (7), 425-441. doi:10.1038/s41571019-0203-7

Liao, Y. H., Li, C. I., Lin, C. C., Lin, J. G., Chiang, J. H., and Li, T. C. (2017). Traditional Chinese medicine as adjunctive therapy improves the long-term survival of lung cancer patients. J. Cancer Res. Clin. Oncol. 143 (12), 2425-2435. doi:10.1007/s00432-017-2491-6

Lin, L. L., Hsia, C. R., Hsu, C. L., Huang, H. C., and Juan, H. F. (2015). Integrating transcriptomics and proteomics to show that tanshinone IIA suppresses cell growth by blocking glucose metabolism in gastric cancer cells. BMC Genom 16 (1), 41. doi:10.1186/s12864-015-1230-0

Lin, P. H., Lin, S. K., Hsu, R. J., Pang, S. T., Chuang, C. K., Chang, Y. H., et al. (2019). Spirit-quieting traditional Chinese medicine may improve survival in prostate cancer patients with depression. J. Clin. Med. 8 (2), 218. doi:10.3390/ jcm8020218

Lin, P. H., Liu, J. M., Hsu, R. J., Chuang, H. C., Chang, S. W., Pang, S. T., et al. (2018). Depression negatively impacts survival of patients with metastatic prostate cancer. Int. J. Environ. Res. Publ. Health 15 (10), 2148. doi:10.3390/ ijerph15102148

Lin, W. C., and Lin, J. Y. (2011). Five bitter compounds display different antiinflammatory effects through modulating cytokine secretion using mouse primary splenocytes in vitro. J. Agric. Food Chem. 59 (1), 184-192. doi:10. 1021/jf103581r

Liu, J., Wang, S., Zhang, Y., Fan, H. T., and Lin, H. S. (2015). Traditional Chinese medicine and cancer: history, present situation, and development. Thorac. Cancer 6 (5), 561-569. doi:10.1111/1759-7714.12270

Liu, T., Zhu, G., Yan, W., Lv, Y., Wang, X., Jin, G., et al. (2020). Cordycepin inhibits cancer cell proliferation and angiogenesis through a DEK interaction via ERK signaling in cholangiocarcinoma. J. Pharmacol. Exp. Ther. 373 (2), 279-289. doi:10.1124/jpet.119.263202

Lu, Y., Lian, S., Ye, Y., Yu, T., Liang, H., Cheng, Y., et al. (2019). S-Nitrosocaptopril prevents cancer metastasis in vivo by creating the hostile bloodstream microenvironment against circulating tumor cells. Pharmacol. Res. 139, 535-549. doi:10.1016/j.phrs.2018.10.020

Luo, M., Shang, L., Brooks, M. D., Jiagge, E., Zhu, Y., Buschhaus, J. M., et al. (2018). Targeting breast cancer stem cell state equilibrium through modulation of redox signaling. Cell Metabol 28 (1), 69-86.e66. doi:10.1016/j.cmet.2018.06.006

Magnon, C., Hall, S. J., Lin, J., Xue, X., Gerber, L., Freedland, S. J., et al. (2013). Autonomic nerve development contributes to prostate cancer progression. Science 341 (6142), 1236361. doi:10.1126/science.1236361

Mariathasan, S., Turley, S. J., Nickles, D., Castiglioni, A., Yuen, K., Wang, Y., et al. (2018). TGF $\beta$ attenuates tumour response to PD-L1 blockade by contributing to exclusion of T cells. Nature 554 (7693), 544-548. doi:10.1038/nature25501

McGranahan, N., and Swanton, C. (2017). Clonal heterogeneity and tumor evolution: past, present, and the future. Cell 168 (4), 613-628. doi:10.1016/j. cell.2017.01.018

Metidji, A., Omenetti, S., Crotta, S., Li, Y., Nye, E., Ross, E., et al. (2018). The environmental sensor AHR protects from inflammatory damage by maintaining intestinal stem cell homeostasis and barrier integrity. Immunity 49 (2), 353-362.e355. doi:10.1016/j.immuni.2018.07.010

Mitroulis, I., Ruppova, K., Wang, B., Chen, L. S., Grzybek, M., Grinenko, T., et al. (2018). Modulation of myelopoiesis progenitors is an integral component of trained immunity. Cell 172 (1-2), 147-161.e112. doi:10.1016/j.cell.2017.11.034

Moses, M. A., Sudhalter, J., and Langer, R. (1990). Identification of an inhibitor of neovascularization from cartilage. Science 248 (4961), 1408-1410. doi:10.1126/ science.1694043

Nagi, R. S., Bhat, A. S., and Kumar, H. (2014). Cancer: a tale of aberrant PRR response. Front. Immunol 5, 161. doi:10.3389/fimmu.2014.00161

Okabe, Y., and Medzhitov, R. (2014). How the immune system spots tumors. Elife 3, e04476. doi:10.7554/eLife.04476
Patra, D., and Sandell, L. J. (2012). Antiangiogenic and anticancer molecules in cartilage. Expet Rev. Mol. Med. 14, e10. doi:10.1017/erm.2012.3

Pearce, O. M. T., Delaine-Smith, R. M., Maniati, E., Nichols, S., Wang, J., Böhm, S., et al. (2018). Deconstruction of a metastatic tumor microenvironment reveals a common matrix response in human cancers. Cancer Discov. 8 (3), 304-319. doi:10.1158/2159-8290.cd-17-0284

Pinquart, M., and Duberstein, P. R. (2010). Depression and cancer mortality: a meta-analysis. Psychol. Med. 40 (11), 1797-1810. doi:10.1017/ s0033291709992285

Powell, N. D., Tarr, A. J., and Sheridan, J. F. (2013). Psychosocial stress and inflammation in cancer. Brain Behav. Immun 30 (Suppl. 1), S41-S47. doi:10. 1016/j.bbi.2012.06.015

Prudden, J. F., Teneick, M. L., Svahn, D., and Frueh, B. (1964). Acceleration of wound healing in various species by parenteral injection of a saline extract of cartilage. J. Surg. Res. 4, 143-144

Prudden, J. F. (1985). The treatment of human cancer with agents prepared from bovine cartilage. J. Biol. Response Modif. 4 (6), 551-584

Qin, P., Li, X., Yang, H., Wang, Z. Y., and Lu, D. (2019). Therapeutic potential and biological applications of cordycepin and metabolic mechanisms in cordycepinproducing fungi. Molecules 24 (12), 2231. doi:10.1016/j.jphs.2014.09.001

Qiu, J. (2007). Traditional medicine: a culture in the balance. Nature 448 (7150), 126-128. doi:10.1038/448126a

Rankin, L. C., and Artis, D. (2018). Beyond host defense: emerging functions of the immune system in regulating complex tissue physiology. Cell 173 (3), 554-567. doi:10.1016/j.cell.2018.03.013

Rapisarda, A., and Melillo, G. (2012). Overcoming disappointing results with antiangiogenic therapy by targeting hypoxia. Nat. Rev. Clin. Oncol. 9 (7), 378-390. doi:10.1038/nrclinonc.2012.64

Rubartelli, A., and Lotze, M. T. (2007). Inside, outside, upside down: damageassociated molecular-pattern molecules (DAMPs) and redox. Trends Immunol 28 (10), 429-436. doi:10.1016/j.it.2007.08.004

Saltiel, A. R., and Olefsky, J. M. (2017). Inflammatory mechanisms linking obesity and metabolic disease. J. Clin. Invest. 127 (1), 1-4. doi:10.1172/jci92035

Schaaf, M. B., Garg, A. D., and Agostinis, P. (2018). Defining the role of the tumor vasculature in antitumor immunity and immunotherapy. Cell Death Dis. 9 (2), 115. doi:10.1038/s41419-017-0061-0

Sennino, B., and McDonald, D. M. (2012). Controlling escape from angiogenesis inhibitors. Nat. Rev. Cancer 12 (10), 699-709. doi:10.1038/nrc3366

Sharma, P., and Allison, J. P. (2015). Immune checkpoint targeting in cancer therapy: toward combination strategies with curative potential. Cell 161 (2), 205-214. doi:10.1016/j.cell.2015.03.030

Shin, K. J., Lee, Y. J., Yang, Y. R., Park, S., Suh, P. G., Follo, M. Y., et al. (2016). Molecular mechanisms underlying psychological stress and cancer. Curr. Pharmaceut. Des 22 (16), 2389-2402. doi:10.2174/ 1381612822666160226144025

Singh, R., Chandrashekharappa, S., Bodduluri, S. R., Baby, B. V., Hegde, B., Kotla, N. G., et al. (2019). Enhancement of the gut barrier integrity by a microbial metabolite through the Nrf2 pathway. Nat. Commun. 10 (1), 89. doi:10.1038/ s41467-018-07859-7

Sung, Y. C., Jin, P. R., Chu, L. A., Hsu, F. F., Wang, M. R., Chang, C. C., et al. (2019). Delivery of nitric oxide with a nanocarrier promotes tumour vessel normalization and potentiates anti-cancer therapies. Nat. Nanotechnol. 14 (12), 1160-1169. doi:10.1038/s41565-019-0570-3

Swart, M., Verbrugge, I., and Beltman, J. B. (2016). Combination approaches with immune-checkpoint blockade in cancer therapy. Front Oncol. 6, 233. doi:10. 3389/fonc.2016.00233

Tamada, S., Ebisu, K., Yasuda, S., Kato, M., Ninomiya, N., Yamasaki, T., et al. (2018). Kamikihito improves cancer-related fatigue by restoring balance between the sympathetic and parasympathetic nervous systems. Prostate Int. 6 (2), 55-60. doi:10.1016/j.prnil.2017.11.002

Tan, Y., Lv, Z. P., Bai, X. C., Liu, X. Y., and Zhang, X. F. (2006). Traditional Chinese medicine bao gan ning increase phosphorylation of CREB in liver fibrosis in vivo and in vitro. J. Ethnopharmacol 105 (1-2), 69-75. doi:10.1016/j.jep.2005. 09.040

Tauriello, D. V. F., Palomo-Ponce, S., Stork, D., Berenguer-Llergo, A., BadiaRamentol, J., Iglesias, M., et al. (2018). TGF $\beta$ drives immune evasion in genetically reconstituted colon cancer metastasis. Nature 554 (7693), 538-543. doi:10.1038/nature25492 
Tlsty, T. D., and Gascard, P. (2019). Stromal directives can control cancer. Science 365 (6449), 122-123. doi:10.1126/science.aaw2368

Traka, M. H., Melchini, A., and Mithen, R. F. (2014). Sulforaphane and prostate cancer interception. Drug Discov. Today 19 (9), 1488-1492. doi:10.1016/j. drudis.2014.07.007

Vafa, A., Afzal, S. M., Barnwal, P., Rashid, S., Shahid, A., Alpashree, et al. (2019). Protective role of diosmin against testosterone propionate-induced prostatic hyperplasia in Wistar rats: plausible role of oxidative stress and inflammation. Hum. Exp. Toxicol. 39 (9), 1133-1146. doi:10.1177/0960327119889655

Vander Heiden, M. G., and DeBerardinis, R. J. (2017). Understanding the intersections between metabolism and cancer biology. Cell 168 (4), 657-669. doi:10.1016/j.cell.2016.12.039

Wang, D., Jiang, Y., Wu, K., Wang, S., and Wang, Y. (2015a). Evaluation of antitumor property of extracts and steroidal alkaloids from the cultivated Bulbus Fritillariae ussuriensis and preliminary investigation of its mechanism of action. BMC Compl. Alternat. Med. 15, 29. doi:10.1186/ s12906-015-0551-5

Wang, N., Feng, Y., Tan, H. Y., Cheung, F., Hong, M., Lao, L., et al. (2015b). Inhibition of eukaryotic elongation factor-2 confers to tumor suppression by a herbal formulation Huanglian-Jiedu decoction in human hepatocellular carcinoma. J. Ethnopharmacol 164, 309-318. doi:10.1016/j.jep.2015.02.025

Wang, N., Tan, H. Y., Li, L., Yuen, M. F., and Feng, Y. (2015c). Berberine and Coptidis Rhizoma as potential anticancer agents: recent updates and future perspectives. J. Ethnopharmacol 176, 35-48. doi:10.1016/j.jep.2015.10.028

Wang, S., Liu, R., Yu, Q., Dong, L., Bi, Y., and Liu, G. (2019). Metabolic reprogramming of macrophages during infections and cancer. Cancer Lett. 452, 14-22. doi:10.1016/j.canlet.2019.03.015

Wei, S. C., Duffy, C. R., and Allison, J. P. (2018). Fundamental mechanisms of immune checkpoint blockade therapy. Cancer Discov. 8 (9), 1069-1086. doi:10. 1158/2159-8290.cd-18-0367

Editorial. (2019). The world health organization's decision about traditional chinese medicine could backfire. Nature 570 (7759), 5. doi:10.1038/d41586-019-01726-1

Wildenrath, C. (1995). [Comeback of the leech. Recombinant hirudin in antithrombosis therapy]. Fortschr. Med. 113 (3), 41

Willyard, C. (2016). Cancer therapy: an evolved approach. Nature 532 (7598), 166-168. doi:10.1038/532166a

Xiao, W., Wu, K., Yin, M., Han, S., Ding, Y., Qiao, A., et al. (2015). Wogonin inhibits tumor-derived regulatory molecules by suppressing STAT3 signaling to promote tumor immunity. J. Immunother 38 (5), 167-184. doi:10.1097/cji. 0000000000000080

Xing, Y., Zhao, S., Zhou, B. P., and Mi, J. (2015). Metabolic reprogramming of the tumour microenvironment. Cancer Res 282 (20), 3892-3898. doi:10.1158/00085472.can-19-0617

Xiu, L. J., Sun, D. Z., Jiao, J. P., Yan, B., Qin, Z. F., Liu, X., et al. (2015). Anticancer effects of traditional Chinese herbs with phlegm-eliminating properties - an overview. J. Ethnopharmacol 172, 155-161. doi:10.1016/j.jep.2015.05.032

Xu, B., Deng, H., Zhang, X., Luo, J., Zhang, G., Zhang, Z., et al. (2018). A novel Danshensu/tetramethylpyrazine derivative induces vasorelaxation on rat aorta and exerts cardioprotection in dogs. Eur. J. Pharmacol 818, 158-166. doi:10. 1016/j.ejphar.2017.10.034

Xu, F., Xu, S., Wang, L., Chen, C., Zhou, X., Lu, Y., et al. (2011). Antinociceptive efficacy of verticinone in murine models of inflammatory pain and paclitaxel induced neuropathic pain. Biol. Pharm. Bull. 34 (9), 1377-1382. doi:10.1248/ bpb.34.1377

Xu, Q., Bauer, R., Hendry, B. M., Fan, T. P., Zhao, Z., Duez, P., et al. (2013). The quest for modernisation of traditional Chinese medicine. BMC Compl. Alternat. Med. 13, 132. doi:10.1186/1472-6882-13-132

Yin, C. F., Kao, S. C., Hsu, C. L., Chang, Y. W., Cheung, C. H. Y., Huang, H. C., et al. (2020). Phosphoproteome analysis reveals dynamic heat shock protein 27 phosphorylation in tanshinone IIA-induced cell death. J. Proteome Res 19 (4), 1620-1634. doi:10.1021/acs.jproteome.9b00836

Zhang, C., Wang, N., Tan, H. Y., Guo, W., Li, S., and Feng, Y. (2018). Targeting VEGF/VEGFRs pathway in the antiangiogenic treatment of human cancers by traditional Chinese medicine. Integr. Cancer Ther. 17 (3), 582-601. doi:10.1177/ 1534735418775828

Zhang, L. J., Chen, L., Lu, Y., Wu, J. M., Xu, B., Sun, Z. G., et al. (2010). Danshensu has anti-tumor activity in B16F10 melanoma by inhibiting angiogenesis and tumor cell invasion. Eur. J. Pharmacol 643 (2-3), 195-201. doi:10.1016/j.ejphar. 2010.06 .045

Zhou, J. Y., Chen, M., Wu, C. E., Zhuang, Y. W., Chen, Y. G., and Liu, S. L. (2019). The modified si-jun-zi decoction attenuates colon cancer liver metastasis by increasing macrophage cells. Evid. Based. Complement. Alternat. Med. 19 (1), 86. doi:10.1155/2019/9860381

Zhuang, X., Zhang, H., and Hu, G. (2019). Cancer and microenvironment plasticity: double-edged swords in metastasis. Trends Pharmacol. Sci. 40 (6), 419-429. doi:10.1016/j.tips.2019.04.005

Zou, M., Chen, Y., Sun-Waterhouse, D., Zhang, Y., and Li, F. (2018). Immunomodulatory acidic polysaccharides from zizyphus jujuba cv. huizao: insights into their chemical characteristics and modes of action. Food Chem. 258, 35-42. doi:10.1016/j.foodchem.2018.03.052

Conflict of Interest: S-HL is a chief technology officer of Celgen Biotech whose nutraceutical products contain $\beta$-glucan, sulforaphane, and bovine tracheal cartilage (BTC) components.

The remaining authors declare that the research was conducted in the absence of any commercial or financial relationships that could be construed as a potential conflict of interest.

Copyright (c) 2021 Liu, Chen, Huang, Hung, Lee, Lin, Lin and Lee. This is an openaccess article distributed under the terms of the Creative Commons Attribution License (CC BY). The use, distribution or reproduction in other forums is permitted, provided the original author(s) and the copyright owner(s) are credited and that the original publication in this journal is cited, in accordance with accepted academic practice. No use, distribution or reproduction is permitted which does not comply with these terms. 